\title{
Biomedical applications of functionalized fullerene-based nanomaterials
}

REVIEW

This article was published in the following Dove Press journal:

International Journal of Nanomedicine

10 November 2009

Number of times this article has been viewed

\section{Ranga Partha \\ Jodie L Conyers}

Center for Translational Injury Research, The University of Texas Health Science Center, Houston, TX 77030, USA
Correspondence: Jodie L Conyers The University of Texas Health Science Center at Houston, Center for Translational Injury Research, Department of Surgery, 64I0 Fannin Street, Suite I I 00.15, Houston, TX 77030, USA

Tel +17135007370

Fax +I 7135127135

Email jodie.I.conyers@uth.tmc.edu
Abstract: Since their discovery in 1985, fullerenes have been investigated extensively due to their unique physical and chemical properties. In recent years, studies on functionalized fullerenes for various applications in the field of biomedical sciences have seen a significant increase. The ultimate goal is towards employing these functionalized fullerenes in the diagnosis and therapy of human diseases. Functionalized fullerenes are one of the many different classes of compounds that are currently being investigated in the rapidly emerging field of nanomedicine. In this review, the focus is on the three categories of drug delivery, reactive oxygen species quenching, and targeted imaging for which functionalized fullerenes have been studied in depth. In addition, an exhaustive list of the different classes of functionalized fullerenes along with their applications is provided. We will also discuss and summarize the unique approaches, mechanisms, advantages, and the aspect of toxicity behind utilizing functionalized fullerenes for biomedical applications.

Keywords: fullerenes, functionalized fullerenes, nanomedicine, drug delivery, buckysomes, radiation protection

\section{Introduction}

Next year will mark 25 years since the third allotrope of carbon, namely fullerenes, were discovered in $1985 .{ }^{1}$ During these 25 years, fullerenes have captured the imagination of scientists due to their unique physical and chemical properties. Buckminsterfullerene $\left(\mathrm{C}_{60}\right)$ is a truncated icosahedron containing 60 carbon atoms with $\mathrm{C}_{5}-\mathrm{C}_{5}$ single bonds forming pentagons and $\mathrm{C}_{5}-\mathrm{C}_{6}$ double bonds forming hexagons. ${ }^{1}$ The diameter of a $\mathrm{C}_{60}$ fullerene molecule is $0.7 \mathrm{~nm}$, hence it is an important member of the nanomaterials family. However, $\mathrm{C}_{60}$ has poor solubility in aqueous solvents coupled with a tendency to form aggregates in aqueous solutions, which makes it an unattractive candidate in biological applications., ${ }^{2,3}$ This problem has been solved to a great extent by various chemical and supramolecular approaches to functionalize fullerenes. ${ }^{4-6}$ Some of the functionalized fullerenes have excellent solubility in polar solvents and easily overcome the hurdles posed by $\mathrm{C}_{60}$.

Nanomedicine, a combinatorial approach using nanotechnology and medicine, has become an increasingly important field of research for diagnostics and theranostics. ${ }^{7-9}$ The field of nanomedicine involves the design and development of novel nanomaterials (Figure 1) such as multifunctional liposomal nanoparticles, ${ }^{10-12}$ functionalized fullerenes, ${ }^{13-15}$ functionalized nanotubes, ${ }^{16}$ iron oxide nanoparticles, ${ }^{17}$ polymeric micelles, ${ }^{18}$ dendrimers, ${ }^{19}$ nanoshells,${ }^{20}$ and polymeric microspheres. ${ }^{21}$ Once engineered, 


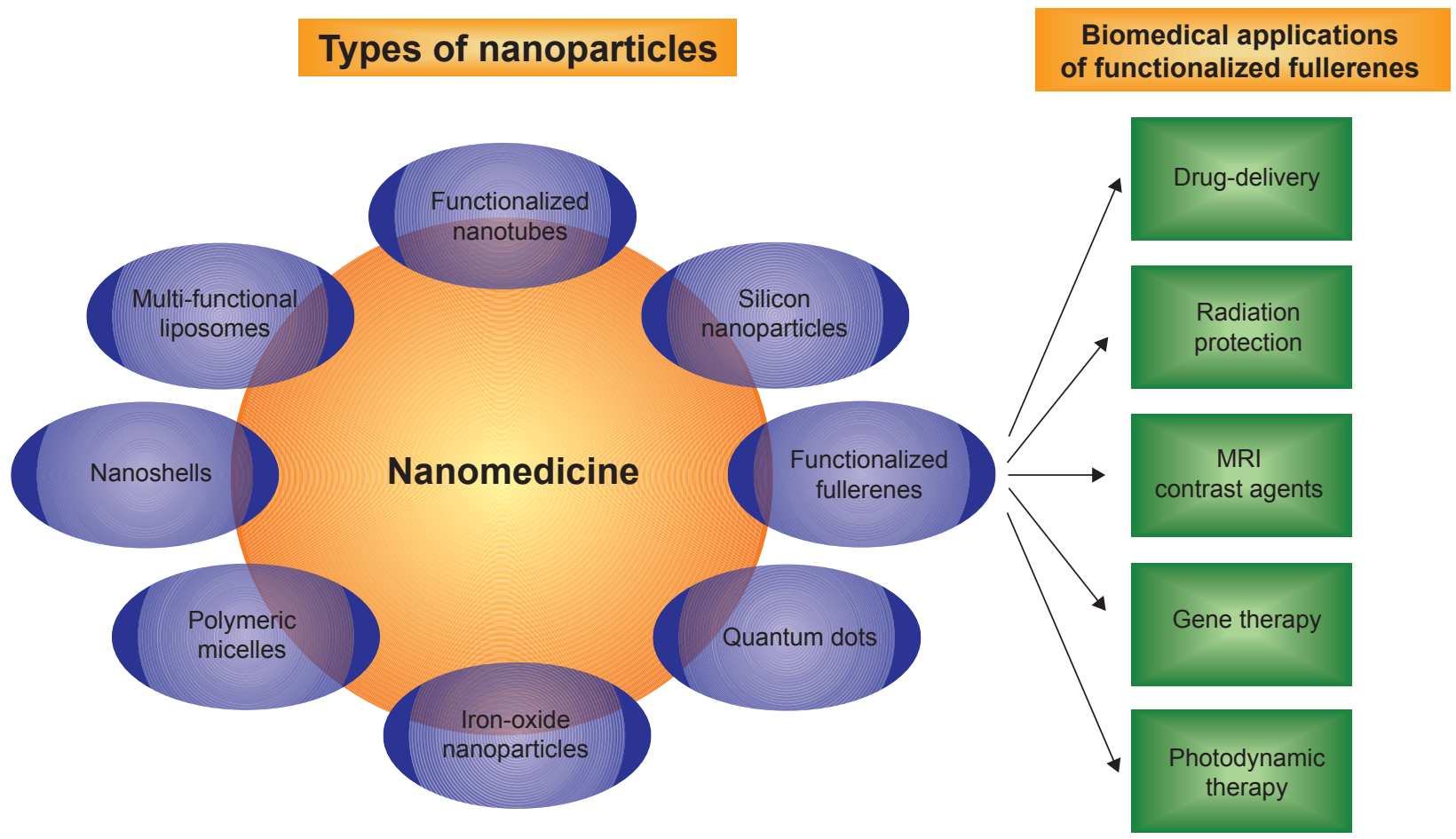

Figure I Schematic represents functionalized fullerenes as an important member of the rapidly emerging and expanding diverse nanomedicine family. Abbreviation: MRI, magnetic resonance imaging.

these novel nanomaterials are then investigated to diagnose and treat major ailments such as cancer, ${ }^{22}$ heart, ${ }^{23}$ lung, and blood diseases. ${ }^{24}$ Drug delivery, ${ }^{25}$ reactive oxygen species (ROS) quenching, ${ }^{26-28}$ and targeted imaging ${ }^{29}$ have been some of the major areas of focus in nanomedicine. ${ }^{7}$

In this review, we discuss the role of functionalized fullerenes as a novel nanomaterial in biomedical applications with regard to the above mentioned three major areas of focus. We summarize the approaches used to functionalize fullerenes, their mechanism of action, comparative advantages of employing functionalized fullerenes and briefly discuss the aspect of toxicity in biological systems. We restrict the scope of this review to articles featuring functionalized fullerenes based on $\mathrm{C}_{60}$ platforms. Even though modification of fullerenes based on $\mathrm{C}_{70}$-based platforms have been well investigated, there is a lack of progress in the in vivo biomedical applications of $\mathrm{C}_{70}$-based platforms in the areas of drug delivery, ROS quenching, and targeted imaging. Since the number of novel functionalized fullerenes is rapidly expanding, we have created an exhaustive list (Table 1) of functionalized fullerenes along with their potential biomedical applications using previous review articles on this topic. ${ }^{30-37}$ In addition, this review will emphasize the clinical applications of a certain group of fullerenes functionalized with amphiphilic and dendritic groups by Hirsch and colleagues. ${ }^{13-15}$ Our research group has been investigating the use of amphiphilic fullerenes ${ }^{38,39}$ and dendritic fullerenes for drug delivery and ROS quenching, respectively. We have successfully demonstrated that amphiphilic fullerenes are capable of forming spherical vesicles in the order of 100-150 nm termed "buckysomes." ${ }^{138}$ These buckysomes can serve as drug delivery vectors to carry hydrophobic drugs such as paclitaxel to destroy cancer cells. ${ }^{39}$

\section{List of functionalized fullerenes}

Table 1 serves as a reference guide and provides a list of functionalized fullerenes that have been investigated for potential applications in biomedicine. The type of functionalized fullerene along with its potential use and the reference article are shown in this table.

The scope of this review is limited to the biological applications of functionalized fullerenes and not the synthesis aspect of modifying fullerenes. However, it is important to emphasize that the potential biological benefits can be realized only through novel modifications to fullerenes. On this note, credit must be given to all the fullerene chemists who have designed fullerenes to make them water soluble and thereby increase its ease of use in a biological system. 
Table I List of functionalized fullerenes and their potential applications in biomedicine

\begin{tabular}{|c|c|c|}
\hline $\begin{array}{l}\text { Type of functionalized fullerene } \\
\text { (Keywords) }\end{array}$ & Potential application & References \\
\hline Amphiphilic fullerene & Drug delivery & Brettreich $^{14}$ \\
\hline \multirow[t]{3}{*}{ (AF-I, buckysomes, PEB) } & & Burghardt $^{15}$ \\
\hline & & Partha $^{38}$ \\
\hline & & Partha $^{39}$ \\
\hline \multirow[t]{2}{*}{ Dendrofullerene (DF-I) } & Radioprotection & Brettreich $^{13}$ \\
\hline & & Daroczii ${ }^{40}$ \\
\hline Fullerene-paclitaxel & Cancer therapy & Zakharian $^{41}$ \\
\hline Fullerene polyamine (tetraamino & Gene delivery, transfection & Nakamura $^{42}$ \\
\hline \multirow[t]{3}{*}{ fullerene) } & & Isobe ${ }^{43}$ \\
\hline & & Isobe ${ }^{44}$ \\
\hline & & Isobe $e^{45}$ \\
\hline Amino-fullerene adducts & Nonviral gene delivery & Sitharaman ${ }^{46}$ \\
\hline Fullerene-based amino acids & Peptide delivery & Bianco $^{47}$ \\
\hline \multirow[t]{2}{*}{ and peptides } & & Yang ${ }^{48}$ \\
\hline & & Yang $^{49}$ \\
\hline \multirow{2}{*}{ Cystine $C_{60}$, Beta-alanine $C_{60}$} & $\mathrm{H}_{2} \mathrm{O}_{2}$-induced apoptosis & $\mathrm{Hu}^{50}$ \\
\hline & Protection & $\mathrm{Hu}^{51}$ \\
\hline Fullerene lipidosome & Anti-viral activity & $\mathrm{ji}^{52}$ \\
\hline \multirow[t]{2}{*}{ Fullerene doped liposomes (LMIC) } & Photodynamic cancer therapy & Ikeda $^{53}$ \\
\hline & & $D_{0 i}{ }^{54}$ \\
\hline Fullerene-liposomes & Antioxidant & Lens $^{55}$ \\
\hline Fullerene vesicle & Oxidative stress reduction & Maeda $^{56}$ \\
\hline \multirow[t]{5}{*}{ Gadofullerenes } & MRI contrast agents & Bolskar ${ }^{57}$ \\
\hline & & Tóth ${ }^{58}$ \\
\hline & & Sitharaman ${ }^{59}$ \\
\hline & & Bolskar ${ }^{60}$ \\
\hline & & Fatouros ${ }^{61}$ \\
\hline \multirow[t]{2}{*}{ Hydrophilic or cationic fullerenes } & Photodynamic cancer therapy & $\operatorname{Mroz}^{62}$ \\
\hline & & $\operatorname{Mroz}^{63}$ \\
\hline Human serum albumin-fullerene & & $\mathrm{Qu}^{64}$ \\
\hline Fullerene hexaadducts & & Rancan ${ }^{65}$ \\
\hline PEG-modified fullerene & & Tabata $^{66}$ \\
\hline \multirow[t]{5}{*}{ Fullerenol } & Free radical scavenger & Dugan $^{67}$ \\
\hline & & Tsai ${ }^{68}$ \\
\hline & & Lai $^{69}$ \\
\hline & & $\operatorname{lnjac}^{70}$ \\
\hline & & $\operatorname{lnjac^{71}}$ \\
\hline Carboxy fullerene & & Dugan $^{72}$ \\
\hline Polymer encapsulated fullerene & & Murthy ${ }^{73}$ \\
\hline \multirow[t]{2}{*}{ Hydrated fullerene } & Treating alcohol-induced & Tykhomyrov ${ }^{74}$ \\
\hline & encephalopathy & \\
\hline Fullerene based nanocationite & Myocardial hypoxia & Amirshahi ${ }^{75}$ \\
\hline C3-F-tris-MDC & Oxidative stress reduction & Bisaglia ${ }^{76}$ \\
\hline Carboxy fullerene & Antioxidant & $\operatorname{Lin}^{77}$ \\
\hline \multirow[t]{2}{*}{ Ascorbic acid-fullerene } & & Monti ${ }^{78}$ \\
\hline & & Santos $^{79}$ \\
\hline Bisphosphonate fullerene & Bone therapeutic agent & Gonzalez $^{80}$ \\
\hline
\end{tabular}

Abbreviations: AF-I, amphiphilic fullerene-I; PEB, paclitaxel-embedded buckysomes; DF-I dendrofullerene-I; LMIC, Lipid membrane incorporated fullerenes; C3-F-tris-MDC, C3-fullero-tris-methanodicarboxylic acid.

In particular, Prof. Andreas Hirsch's group at University Erlangen-Nuremberg, Germany, Prof. Maurizio Prato's group at University of Trieste, Italy, and Prof. Lon Wilson's group at Rice University, Texas, USA are pioneers in the design and synthesis of water soluble fullerenes.
Hirsch and colleagues have investigated the synthesis of supramolecular organization of dendritic amphiphiles that contain fullerenes or calixarenes as core units. ${ }^{13-15}$ The "amphifullerene" compounds, which are based on a $\mathrm{C}_{60}$ core, contain both hydrophobic (water-insoluble) and 
hydrophilic (water-soluble) moieties and self-assemble to form supramolecular structures referred to as "buckysomes." 38 These buckysomes are the first reported instance of a watersoluble fullerene that is capable of forming a vesicle through instantaneous self-assembly. Amphiphilic fullerene-1 (AF-1) is one such novel functionalized fullerene which can selfassemble into either a hydrophilic vesicle with a hollow interior $^{38}$ or a solid spherical nanostructure with a dense hydrophobic interior. ${ }^{39}$ The fullerene monomer AF-1, consists of a "buckyball" cage to which a Newkome-like dendrimer unit and ten hydrophobic $\mathrm{C}_{12}$ chains positioned octahedrally to the dendrimer are attached (Figure 2). The functional group at the top of the molecule is a dendritic moiety containing 18 carboxylic acid groups. At the other five positions are pairs of $\mathrm{C}_{12}$ esters (dodecyl malonates). A recent collaborative effort between our group and Prof. Hirsch's revealed that by increasing the temperature during the buckysome selfassembly process, AF-1 forms a novel vesicular structure with the ability to encapsulate hydrophobic molecules. ${ }^{39}$ These results were highly encouraging towards investigating the use of buckysomes as novel "nanovectors," which deliver drugs to specific disease sites in the human body.

Buckminsterfullerenes are characterized as a "radical sponge" for their ability to add multiple radicals per each fullerene molecule. ${ }^{26}$ However, this radical scavenging feature can be exploited in a biological setting only when the molecule's water solubility is enhanced. In 1994, Hirsch and Lamparth first reported the synthesis of watersoluble malonic acid derivatives of $\mathrm{C}_{60}$ with a defined threedimensional structure. In a landmark research study, Dugan and colleagues ${ }^{72}$ used this Hirsch method to synthesize two specific regioisomers of carboxyfullerenes and demonstrated that they are effective radical scavengers and act as neuroprotective antioxidants in vitro and in vivo. EPR data from their study confirmed that these carboxyfullerenes retained the free radical scavenging potency of the parent fullerene molecule. Also, the neuroprotective efficacy of the carboxyfullerenes was enhanced due to their ability to react with superoxide radical in addition to hydroxyl radical. They further noted that the ability of these carboxyfullerenes to eliminate the superoxide radical before its conversion to the hydroxyl radical is a critical feature of their biologically relevant antioxidant properties. These malonic acid adducts of $\mathrm{C}_{60}$ are highly water soluble, have a well defined structure and exhibit stability. In 1998, the Hirsch group designed highly soluble monoadducts instead of the earlier reported trisadducts for neuroprotective applications. ${ }^{13} \mathrm{~A}$ dendrimer containing 18 carboxylic acid groups was added as an addend to $\mathrm{C}_{60}$
A

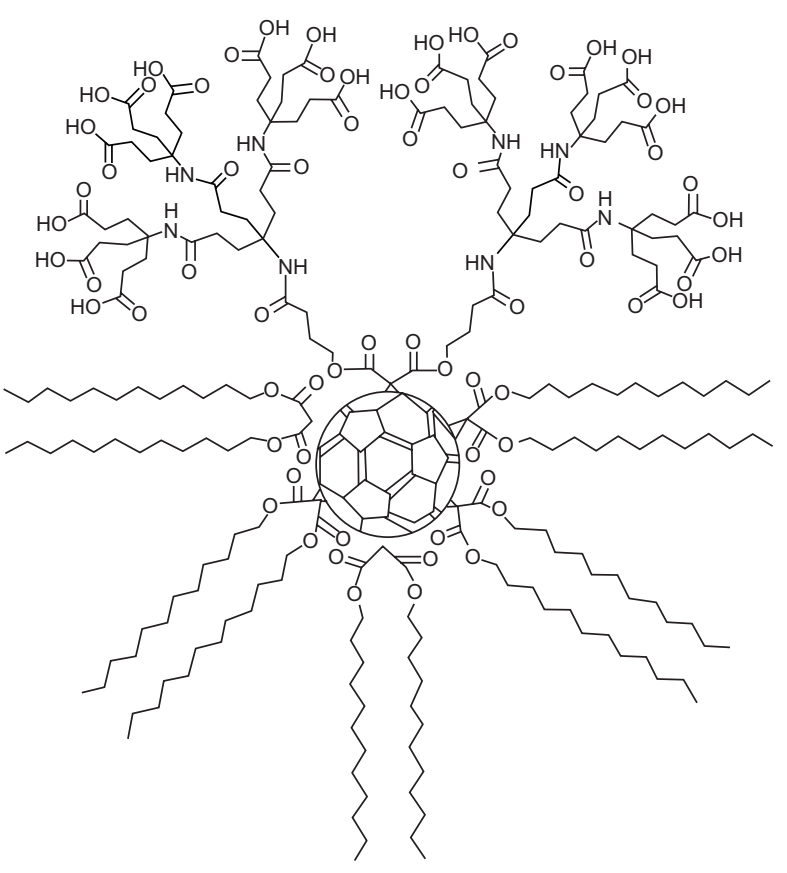

B

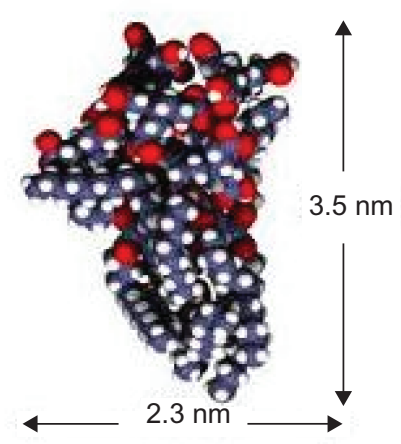

Figure 2 A) The chemical structure of the amphiphilic fullerene (AF-I) monomer; B) Space-filling model of AF-I, depicting its length and width. 
to give rise to a dendro[60]fullerene also known as DF-1. This novel functionalized fullerenes has shown remarkable antioxidant properties against the dangerous effects of ionizing radiation. ${ }^{40}$

Wilson and colleagues have been leaders in the pursuit of using gadolinium ( $\mathrm{Gd}$ )-containing metallofullerenes termed "gadofullerenes" as new generation magnetic resonance imaging (MRI) contrast agents. ${ }^{57-60}$ For the first time, they demonstrated the use of a water-soluble Gd@ $\mathrm{C}_{60}\left[\mathrm{C}(\mathrm{COOH})_{2}\right]_{10}$ derivative as a MRI contrast agent with a favorable biodistribution similar to existing clinically employed MRI contrast agents. ${ }^{57}$ The use of carboxyl functional groups to water solubilize the Gd-metallofullerenes had positive outcomes on excess reticuloendothelial system (RES) uptake, which was an issue of concern with polyhydroxylated fullerene derivates. To avoid the release of the metal ion in vivo during the metabolic processes, the technique of trapping the $\mathrm{Gd}^{3+}$ ion within a fullerene cage for each gadofullerene prevented the dissociation of the metal ion in vivo. ${ }^{59}$ Tóth and colleagues concluded that derivatized $\mathrm{Gd} @ \mathrm{C}_{60}$ nanomaterials in the order of $1.0 \mathrm{~nm}$ diameter offered paradigms in the nanoscale range for designing high performance MRI contrast agent probes which can be up to 20 times more efficient than current clinical contrast agents. ${ }^{58}$

During the past two decades, Prato's group has played a leading role in the fields of synthesizing functionalized fullerenes, purification, and applications. ${ }^{33,47,80-84}$ They used software to model the fullerenes and proceeded to synthesize water-soluble fullerene derivatives. These were targeted to fit inside the hydrophobic cavity of human immunodeficiency virus (HIV) proteases thereby inhibiting the access of substrates to the catalytic site of the enzyme. ${ }^{81}$ The presence of two ammonium groups located on the spheroid surface of the fullerene moiety was considered to be critical elements for the anti-HIV activity. Recently, the synthesis of regioisomeric bis-fulleropyrrolidines bearing two ammonium groups was reported. ${ }^{82}$ The activities of two trans isomers against HIV-1 and HIV-2 were evaluated. The antiviral properties were attributed to the relative positions of the substituent on a $\mathrm{C}_{60}$ cage. In a review article published five years ago, Prato and colleagues discuss clearly the advances of fullerene chemistry in the field of medicinal chemistry. ${ }^{84}$ They explain the synthesis of the biggest unnatural amino acid 3,4-fulleroproline (Fpr) and the ability of Fpr derivatives to interact with various hydrolytic enzymes and selectively discriminate between rationally designed peptides. The review provides valuable information on the capabilities of fullerene-based peptides to activate enzymes involved in the oxidative deamination of biogenic amines.

Fullerenes have also been functionalized in a variety of other methods to make them suitable for biomedical applications. "Fullerenols" are polyhydroxylated fullerenes $\left(\mathrm{C}_{60}(\mathrm{OH})_{\mathrm{n}} ; \mathrm{n}=12-26\right)$ and are considered excellent antioxidants due to their free radical scavenging ability. ${ }^{67-71}$ As described earlier, fullerene-containing amino acids have been found to substantially modulate enzymatic activity and provide further insight into the structure-function relationship of proteins and enzymes. ${ }^{47-51}$ Another interesting method involves incorporating fullerenes either into the bi-layers of lipsomes termed lipid membrane incorporate fullerenes (LMIC) $)^{53,54}$ or encapsulating inside the liposomes. ${ }^{55,56}$ Other novel methods include complexing human serum albumin with functionalized fullerenes, ${ }^{63}$ poly-ethylene glycol (PEG)modified fullerenes, ${ }^{66}$ encapsulation of fullerenes in sugarbased polymer, ${ }^{73}$ adsorption of ascorbic acid on fullerenes, ${ }^{79}$ and a fullerene-paclitaxel chemotherapeutic. ${ }^{41}$ In summary, there is a large variety of methods to functionalize fullerenes to make them suitable in a biological setting. The method clearly is driven and governed by the potential application and toxicity profiles.

\section{Biomedical applications of functionalized fullerenes}

As shown in Table 1, functionalized fullerenes have a versatile and rapidly expanding list of biomedical applications. We will discuss the three major areas of drug delivery, ROS quenching, and role of MRI contrast agents in detail. We will also provide brief information on other potential applications of functionalized fullerenes in the fourth section.

\section{Functionalized fullerenes as drug-delivery nanoparticles}

Paclitaxel-embedded buckysomes (PEBs) are spherical nanostructures in the order of 100-200 nm composed of the amphiphilic fullerene, AF-1 embedding the anti-cancer drug paclitaxel inside its hydrophobic pockets. ${ }^{39}$ Similar to Abraxane $^{\circledR}$, the US Food and Drug Administration (FDA)approved drug for treating diseases such as metastatic breast cancer, our water-soluble fullerene derivatives enable the uptake of paclitaxel without the need for nonaqueous solvents, which can cause patient discomfort and other unwanted side effects. However, our preliminary studies indicate that PEBs might be capable of delivering even higher amounts of paclitaxel than those delivered via Abraxane ${ }^{\circledR}$. By delivering an increased amount of paclitaxel, we can 
hope to reduce infusion times and expect higher tumor uptake, resulting in a greater anticancer efficacy. Another attractive feature of our fullerene-based delivery vectors is that their nanoscale dimensions favor passive targeting, which enables them to accumulate at tumor sites by entering through leaky vasculature present in the endothelial cells of the tumor tissue. Additionally, the fullerene moiety can be easily functionalized to attach targeting agents, which facilitate active targeting. PEBs also provide an easy feature of adding targeting groups to their fullerene moieties. In PEBs, both liposomal and nanoparticle technologies are combined to create nanostructures that function as novel drug carriers. This approach is advantageous because it may improve circulation times in the blood, shields the anticancer drug against enzymatic degradation and reduces uptake by the reticuloendothelial system (RES). The size of the PEBs is designed to be less than $200 \mathrm{~nm}$ to avoid RES uptake. The presence of dendritic groups on the outside of the PEBs can also provide stealth function to reduce clearance.
We have previously described the effects of $\mathrm{pH}$ and various aqueous buffers (solvents) on the self-assembly of AF-1 into buckysomes. ${ }^{38}$ Interestingly, we found that buckysomes prepared at $70{ }^{\circ} \mathrm{C}$ (Figure 3 ) possess morphology conducive to the uptake of hydrophobic molecules. ${ }^{39}$ Notably, the dark contrast observed in the interior of these structures in cryo-electron microscopy images (Figure 3A) most likely corresponds to the presence of densely assembled aggregates of AF-1 monomers. The structures were confirmed using complementary freeze fracture (Figure $3 \mathrm{~B}$ ) and transmission electron microscopy (Figure 3C) techniques. To determine the efficacy of PEBs as an anticancer nanocarrier, we performed in vitro cell viability assays with MCF-7 human breast cancer cells using the trypan blue dye exclusion method (Figure 3, bottom left). Importantly, the empty buckysomes (B) did not hinder cell growth as compared to the buffer (A), demonstrating that the bucksyomes themselves were not cytotoxic. Interestingly, the results obtained with PEBs and Abraxane ${ }^{\circledR}$ was quite comparable. We believe that our
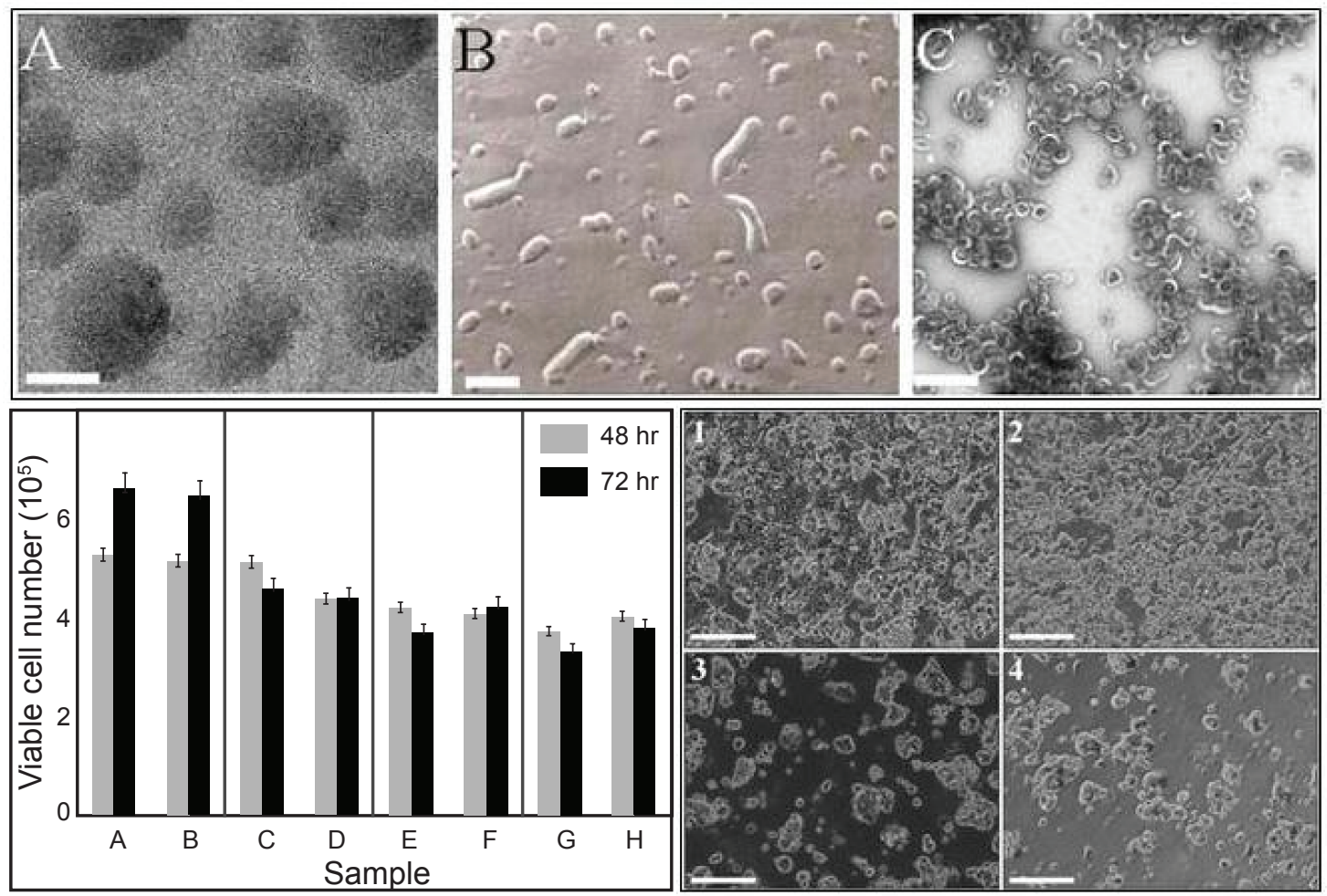

Figure 3 Functionalized fullerenes can function as drug-delivery agents for chemotherapy. Top. A) Cryo-EM image showing the solid, dense spherical structures obtained upon self-assembly of AF-I monomers at an elevated temperature of $70^{\circ} \mathrm{C}$; scale bar $=100 \mathrm{~nm}$. B) Freeze-fracture micrograph (scale bar $=200 \mathrm{~nm}$ ) and $\mathbf{C}$ ) transmission electron micrograph (scale bar: $=500 \mathrm{~nm}$ ) confirm the spherical morphology of the buckysomes in panel $\mathrm{A}$ and also indicate a similar size profile. All three images were obtained from the same buckysome sample. Bottom. (Left) Trypan blue dye-based cell viability assay of MCF-7 cells. Samples were incubated for a period of 48 (gray bars) and $72 \mathrm{~h}$ (black bars) at $37^{\circ} \mathrm{C}$. Negative controls were $0.48 \mathrm{mM}$ citrate buffer A) and empty buckysomes B). The concentration of paclitaxel in the PEBs was $28.6 \mathrm{C}$ ), I 43 E), and 7 I $4 \mathrm{ng} / \mathrm{ml}$ G). The comparative positive control was Abraxane, with identical paclitaxel concentrations in columns D, F, and H, respectively. Bottom (Right) Microscopic visualization of the morphology of live MCF-7 cells incubated with citrate buffer (I), empty buckysomes (2), PEBs (3), and Abraxane (4) for a 72-h time period. The concentration of paclitaxel in images 3 and 4 is $714 \mathrm{ng} / \mathrm{ml}$. These images were collected from the same samples used in the assay shown in left. The scale bars in all four images are $250 \mu \mathrm{m}$. Copyright $($ ) 2008, American Chemical Society. Reprinted with permission from Partha R, Mitchell LR, Lyon JL, Joshi PP, Conyers JL. Buckysomes: fullerene-based nanocarriers for hydrophobic molecule delivery. ACS Nano. 2008;2(9):1950-1958. 
nanocarrier without a stabilizing agent such as albumin can deliver paclitaxel in higher quantities to the cancer cells by endocytosis. During the course of the MCF-7 cell viability assay we simultaneously monitored the cells' morphological changes using optical microscopy. The images (Figure 3, bottom right) clearly correlated with the results obtained in the viability studies. These observations again confirmed that the empty buckysomes were not cytotoxic. The images in panels 1 and 2 differ remarkably from those observed upon delivery of $714 \mathrm{ng} / \mathrm{ml}$ of paclitaxel by both the PEBs (inset 3) and Abraxane ${ }^{\circledR}$ (inset 4) at 72 hours. In both of these cases, MCF-7 cells are sparser in appearance, indicating that the delivered paclitaxel hindered the cell division process. We observed similar results at 48 hours. These in vitro studies have demonstrated that PEBs' efficacy toward MCF-7 human breast cancer cells is comparable to that of Abraxane ${ }^{\circledR}$, and we are currently investigating PEBs in preclinical trials using murine models as a necessary step toward clinical testing and ultimate approval of the PEBs for human use. At the conclusion of these studies, we will be able to determine whether our fullerene-based nanoparticle carriers are an effective core technology for enhanced paclitaxel delivery in vivo.

The ability of fullerene to produce an ideal lipophilic slow-release system and provide three-dimensional scaffolding for covalent attachment of multiple drugs can be used to create single-dose "drug cocktails." In the article by Zakharian and colleagues, a fullerene-paclitaxel conjugate was designed to slowly release the drug for aerosol liposome delivery of paclitaxel for lung cancer therapy. ${ }^{41}$ The aggregate size range for this conjugate was in the order of 120-145 nm and the size did not vary with concentration. This conjugate was designed to release paclitaxel via enzymatic hydrolysis with a half-life of release of $80 \mathrm{~min}$ in bovine plasma. A dilauroylphosphatidylcholine (DLPC)-based liposome formulation of the conjugate was reported to have a half maximal inhibitory concentration $\left(\mathrm{IC}_{50}\right)$ value virtually identical to the $\mathrm{IC}_{50}$ for a paclitaxel-DLPC formulation in human epithelial lung carcinoma A549 cells. They concluded that with both clinically relevant kinetics of hydrolysis and significant cytotoxicity in tissue culture, the fullerenepaclitaxel conjugate had potential for enhanced therapeutic efficacy of paclitaxel in vivo.

Aside from delivering drug molecules, functionalized fullerenes have also been examined as transfection vectors to deliver exogenous DNA into cells and tested for their ability to mediate gene transfer. ${ }^{42-45}$ This technique has possible benefits in gene therapy. Although the first generation fullerene transfection vectors showed promise, they also exhibited high cytotoxicity. ${ }^{44}$ Sitharaman and colleagues successfully demonstrated that a new class of water-soluble $\mathrm{C}_{60}$ derivatives prepared using Hirsch-Bingel chemistry can uptake DNA, transport them across the cell and elicit gene expression. ${ }^{46}$ However, the study shows that only two positively charged $\mathrm{C}_{60}$ derivatives, an octa-amino derivatized $\mathrm{C}_{60}$ and a dodeca-amino derivatized $\mathrm{C}_{60}$ vector, showed efficient in vitro transfection. Aggregation behavior was presumed to cause increased cytotoxicity of certain functionalized fullerenes. Therefore, it was suggested that future studies should address this issue of aggregation in the presence of DNA before designing the derivative. They have also suggested the possibility to develop analogous gadofullerene vectors for a combinatorial approach of diagnosis and therapy.

\section{Reactive oxygen species (ROS) quenching by functionalized fullerenes}

Ever since Krusic and colleagues documented the potential of fullerenes to scavenge $\operatorname{ROS}^{26}{ }^{2}$ there has been a great interest in using fullerenes as an antioxidant. However, it is important to remember that while functionalizing fullerenes to make them water soluble, the free radical scavenging properties must be maintained. In 1997, Dugan and colleagues published a pathbreaking article on "carboxyfullerenes as neuroprotective agents." 72 They suggested that $\mathrm{C}_{60}$ derivatives might constitute antioxidant compounds useful in biological systems. Carboxyfullerene were efficient against excitotoxic necrosis and provided protection against two forms of neuronal apoptosis. This led to the idea that oxidative stress is a critical downstream mediator in disparate necrotic and apoptotic neuronal deaths. The study also showed that amphiphilicity is a desirable feature in the functionalization, increasing intercalation into brain membranes and neuroprotective efficacy. The article demonstrated that $\mathrm{C}_{60}$ derivatives can indeed function as neuroprotective drugs in vivo.

In another study, Lin and colleagues presented in vitro data demonstrating that carboxyfullerenes possesses an antioxidative property and is capable of suppressing ironinduced lipid peroxidation. ${ }^{77}$ Their in vivo study showed neuroprotection by carboxyfullerene against iron-induced degeneration of the nigrostriatal dopaminergic system. Also, they reported that the intranigral infusion of carboxyfullerene appeared to be nontoxic to the nigrostriatal dopaminergic system of rats. Other research studies that followed, confirmed the protective activity of carboxyfullerenes against oxidative stress and their potential as a free radical scavenger. 
Monti and colleagues found that carboxyfullerene was able to protect quiescent human peripheral blood mononuclear cells from apoptosis by a mechanism partially involving the mitochondrial membrane potential integrity, known to be associated with early stages of apoptosis. ${ }^{78}$ They concluded that these results represented the first indication for a target activity of buckminsterfullerenes on cells of the immune system and their mitochondria.

Dicker and colleagues tested the hypothesis that the antioxidant properties of the dendrofullerene, DF-1, would help alleviate the toxicity from radiation exposure. ${ }^{40}$ They compared the effect of DF-1 with the FDA-approved drug amifostine in vivo in a zebrafish (Danio rerio) model. The article reported that radiation exposure of zebrafish embryos produced extensive edema in the developing fish, and this effect was reversed by DF-1 treatment. To obtain a more detailed view of DF-1-mediated radioprotection, they evaluated the effects of this drug on organ-specific, radiation-induced damage. They assessed the effects of DF-1 on a commonly observed phenotype that was apparent within one to two days following ionizing radiation exposure (10-40 Gy) of zebrafish. This phenotype described as "curly-up" or cup and was ascribed to defects in midline development of zebrafish embryos. The study concluded that throughout the dose range tested, DF-1 markedly reduced the incidence of cup. Depending on the ionizing radiation dose, it either reduced the severity or abolished the dorsal curvature altogether (Figure 4). It was significant to note that DF-1 did not cause any adverse effects on normal zebrafish morphology or viability in the concentration range tested $(1-1,000 \mu \mathrm{mol} / \mathrm{L})$. DF-1 $(100 \mu \mathrm{mol} / \mathrm{L})$ was reported to markedly attenuate overall and organ-specific radiation-induced toxicity when given within three hours before or up to 15 minutes after radiation exposure. However, DF-1 did not afford protection when given 30 minutes after ionizing radiation. The degree of radioprotection of DF-1 was comparable with amifostine ( $4 \mathrm{mmol} / \mathrm{L})$. The study also showed that protection against radiation-associated toxicity using DF-1 in zebrafish embryos was associated with marked reduction of radiationinduced ROS. In summary, the authors concluded that DF-1 offered excellent antioxidant properties against radiationinduced damage. This study has implications in developing drugs for the military in the event of radiation attacks.

Chen and colleagues ${ }^{28}$ reported that three different types of water-soluble fullerenes materials can intercept all of the major physiologically relevant ROS. They used a carboxyfullerene derivative $\left[\mathrm{C}_{60}\left(\mathrm{C}(\mathrm{COOH})_{2}\right)_{2}\right]$ and a fullerenol derivative $\left[\mathrm{C}_{60}(\mathrm{OH})_{22}\right]$, and $\mathrm{C}_{82}$-derived gadofullerene. The study demonstrated that these functionalized fullerenes can protect cells against hydrogen peroxide-induced oxidative damage, stabilize the mitochondrial membrane potential and reduce intracellular ROS production. The study reported
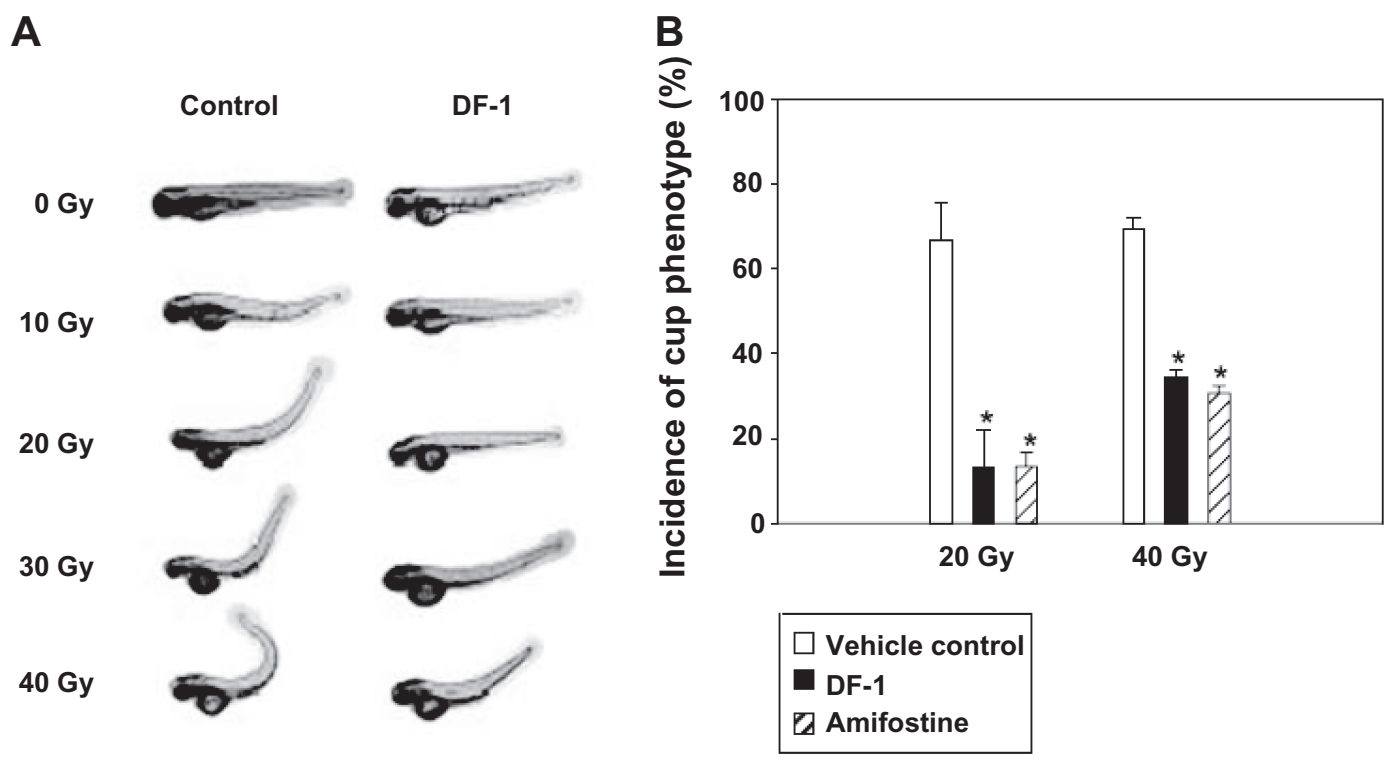

Figure 4 Functionalized fullerenes offers protection from radiation-induced cell damage. DF-I protects against radiation-induced defects in midline development. Radiation-induced morphologic changes in body axis were assessed at 3 dpf. Representative pictures of ionizing radiation-induced dorsal curvature (cup phenotype) in zebrafish and attenuation of this effect by DF-I ( $100 \mu \mathrm{mol} / \mathrm{L})$ given three hours before ionizing radiation ( 24 hpf). Quantitative representation of the results after 20 or $40 \mathrm{~Gy}$ ionizing radiation as indicated. Copyright (C) 2006, American Association for Cancer Research, Inc. Reprinted with permission from Daroczi B, Kari G, McAleer MF, Wolf JC, Rodeck U, Dicker AP. In vivo radioprotection by the fullerene nanoparticle DF-I as assessed in a zebrafish model. Clin Cancer Res. 2006; I2(23):7086-709I.

Notes: $* P=0.0077$, statistically significant differences between control and experimental groups. 
that size of the nanoparticles can affect antioxidant and ROS quenching potency. The explanation was that a suspension of larger nanoparticles would provide less reactive sites for the ROS, thereby reducing the efficiency of scavenging reactive species. In addition, size may influence the distribution of nanoparticles in cells and in tissues. In vitro studies using human lung adenocarcinoma cell line A549 and rat brain capillary endothelial cell line (rBCECs) indicated that these functionalized fullerenes reduces hydrogen peroxide-induced cytotoxicity, free radical formation, and mitochondrial damage (Figure 5). This result indicates that the gadofullerene derivative protected against oxidative injury to cellular mitochondria better than other two fullerene derivatives. Their study represented the first report that different types of fullerene derivatives can scavenge all physiologically relevant ROS. The article concluded that the role of oxidative stress and damage in the etiology and progression of many diseases suggests that these fullerene derivatives may be valuable in vivo cytoprotective and therapeutic agents.

\section{Role of functionalized fullerenes as MRI contrast agents}

Endohedral metallofullerenes are another class of functionalized fullerenes that can encapsulate the metal atom inside the fullerene cage. The ability to design water-soluble derivatives of endohedral metallofullerenes has played a key role in utilizing these compounds for medicinal applications. Analogous to a liposome protecting its encapsulated drug, the fullerene cage in a metallofullerene protects the metal inside both against chemical or enzymatic activity within the body and the unwarranted release of the metal. In this context, Gadolinium-encapsulated fullerenes have been proposed as contrast agents to enhance MRI quality. ${ }^{56-61}$ Another feature of the gadofullerenes as a contrast agent for MRI is ensuring the metal atom is held within the cage for applications that might require longer residency times. Tóth and colleagues were the first to report the nuclear magnetic relaxation profiles for two water-soluble functionalized fullerenes, namely $\mathrm{Gd} @ \mathrm{C}_{60}(\mathrm{OH})_{x}$ and $\mathrm{Gd} @ \mathrm{C}_{60}\left[\mathrm{C}(\mathrm{COOH})_{2}\right]_{10}{ }^{58}$ They concluded that the strong $\mathrm{pH}$ dependency of the proton relaxivities made these functionalized fullerenes great candidates for MRI contrast agents with a stimulus based on $\mathrm{pH}$.

In a follow-up study, Sitharaman and colleagues showed that the anionic gadofullerene $\left\{\mathrm{Gd} @ \mathrm{C}_{60}\left[\mathrm{C}(\mathrm{COOH})_{2}\right]_{10}\right\}$ was an attractive candidate for ex vivo labeling and noninvasive in vivo tracking of any mammalian cell via MRI. ${ }^{59}$ The experiments on cellular internalization experiments indicated that complete labeling of the anionic gadofullerene was achieved for marrow stromal cells within 2-8 hours of incubation with further increase in uptake beyond the eight-hour time point. Also, the supernatant obtained from the pulse-chase experiments showed no detectable Gd content, whereas the cells showed similar Gd concentrations at all time points. Based on these findings, they indicated that the gadofullerene did not leach after labeling and that the labeling process is irreversible under these conditions.
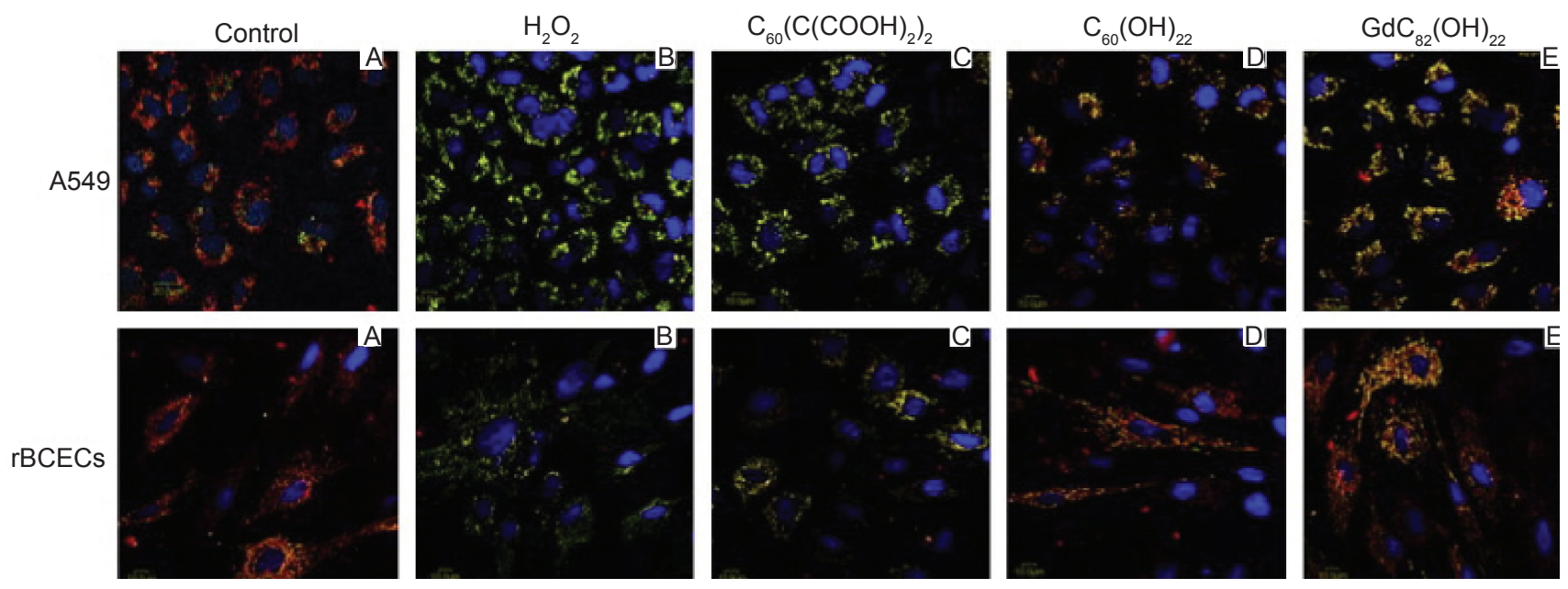

Figure 5 Functionalized fullerenes can play a protective role against hydrogen peroxide induced mitochondrial damage. The protective effects of three fullerene derivatives $\mathrm{Gd@C_{82 }}(\mathrm{OH})_{22}, \mathrm{C}_{60}(\mathrm{OH})_{22}$, and $\mathrm{C}_{60}\left(\mathrm{C}(\mathrm{COOH})_{2}\right)_{2}$ against $\mathrm{H}_{2} \mathrm{O}_{2}$-induced mitochondrial damage in $\mathrm{A} 549$ cells, and rBCEC cells. The cells were treated with I00 $\mu \mathrm{m}$ fullerene derivatives before incubation with $50 \mu \mathrm{m} \mathrm{H}_{2} \mathrm{O}_{2}$. Aggregation of the dye, JC-I, seen as red fluorescence, indicates integrity of the mitochondrial membrane. Copyright (C) 2009, Elsevier. Reprinted with permission from Yin JJ, Lao F, Fu PP, et al. The scavenging of reactive oxygen species and the potential for cell protection by functionalized fullerene materials. Biomaterials. 2009;30(4):6II-62I. 
The results also indicated that cellular labeling with this fullerene derivative is intracellular and/or that the magnetic labels are intercalated deep within the cell membrane. In vitro cell viability and toxicity assays revealed no cell damage as a result of this labeling. $\mathrm{T}_{1}$-weighted MRI phantoms from the study clearly demonstrated that the signal intensity of $\mathrm{Gd} @ \mathrm{C}_{60}\left[\mathrm{C}(\mathrm{COOH})_{2}\right]_{10}$ was about 300\% greater than that of clinically used Gd-DTPA (Magnevist ${ }^{\mathrm{TM}}$ ) at $0.04 \mathrm{mM}$ concentration of gadolinium. They also concluded that at the same concentration of Gd, commercially available Gd-DTPA yielded little enhancement compared with plain distilled water. They also stated that the high relaxivity of the gadofullerenes substantially reduced the $T_{1}$ of labeled cells, even at modest concentrations of gadolinium, and this difference in $T_{1}$ between labeled and unlabeled cells might allow for their direct discrimination with clinical MRI imagers at $1.5 \mathrm{~T}$. According to the study, this is significant for detection of stem cells, by MRI at resolutions that can potentially be achieved in vivo in animals and humans. Fatouros and colleagues conducted studies on water-soluble $\mathrm{Gd}_{3} \mathrm{~N}$ endohedral metallofullerenes functionalized with poly(ethylene glycol) and multihydroxyl groups $\left[\mathrm{Gd}_{3} \mathrm{~N} @\right.$ $\mathrm{C}_{80}\left[\mathrm{DiPEG} 5000(\mathrm{OH})_{\mathrm{x}}\right]$ and demonstrated that they offer great potential for serving as MRI contrast agents due to their $\mathrm{T}_{1}-\mathrm{T}_{2}$ relaxivity characteristics - approximately 40 times greater than conventional gadolinium-containing MRI contrast agents. ${ }^{61}$

\section{Other potential applications}

Fullerenes have the unique ability to quench ROS and generate ROS under specific conditions. Fullerenes have an extended $\pi$-conjugation which allows them to absorb visible light and have a long-lived triplet yield. This property results in the generation of ROS upon illumination with light. This special of ROS generation has resulted in the possible role of fullerenes in photodynamic therapy (PDT). PDT involves the combination of nontoxic photosensitizers and harmless visible light to generate ROS and kill cells. Depending on the functionalized fullerene, they can effectively photoinactivate either or both pathogenic microbial cells and malignant cancer cells. Mroz and colleagues described this mechanism to involve superoxide anion as well as singlet oxygen, and under the right conditions fullerenes to have possible benefits over clinically applied photosensitizers for mediating photodynamic therapy of certain diseases. ${ }^{63}$

The formation of intracellular ROS was shown by Mroz and colleagues in a study that demonstrated that functionalized fullerenes with pyrrolidinium groups mediated photodynamic killing of cancer cells. ${ }^{62}$ They used a reactive intracellular probe to determine if ROS (particularly hydrogen peroxide) were produced in cells that had been incubated with fullerenes and illuminated. Figure 6 shows the fluorescence micrographs of illuminated murine cancer cells that had been incubated with either the probe without fullerene (panel A) or the functionalized fullerene for 24 hours followed by the probe (panel B). There was only trace green fluorescence visible in cells with probe alone, while the cells that had both fullerene and probe demonstrated a large increase in fluorescence that was evenly distributed throughout the cells. The result was consistent with a diffusible species such as hydrogen peroxide having been produced during illumination. The study concluded that monocationic fullerene is a highly effective photo sensitizer for killing cancer cells by rapid induction of apoptosis after illumination and the mechanism involved type I and type II processes. Various other functionalized fullerene derivatives, have been previously investigated to carry out PDT-induced killing of mammalian cells in tissue culture, ${ }^{65}$ and another reported on regressions after PDT in a mouse tumor model. ${ }^{66}$ Fullerene incorporated liposomes have also been studied for photodynamic activity. ${ }^{53-55}$

Functionalized fullerenes with peptides and amino acids have been found to substantially activate enzymes involved in the oxidative deamination of biogenic amines. ${ }^{47}$ The presence of the fullerene-substituted amino acid in a peptide was reported to have a significant effect on the secondary structures and self-assembly properties of peptides as compared to the native peptide. ${ }^{48}$ Gonzalez and colleagues reported for the first time that a fullerene-based material can be successfully targeted to a selected tissue. ${ }^{79}$ A tissuevectored bisphosphonate fullerene designed to target bone tissue was synthesized and evaluated in vitro. The idea was that an amide bisphosphonate addend, in conjunction with multiple hydroxyl groups, confered a strong affinity for the calcium phosphate mineral hydroxyapatite of bone. Table 1 provides a list of references which have investigated functionalized fullerenes for many other potential biomedical applications.

\section{Aspect of toxicity}

The rapid growth of nanotechnology in the past two decades has generated intense discussions on the safety and toxicity aspect of nanomaterials upon accidental exposure to humans and the environment itself. ${ }^{85,86}$ The need to address this aspect has strengthened since a large number of these nanomaterials have potential for usage in 

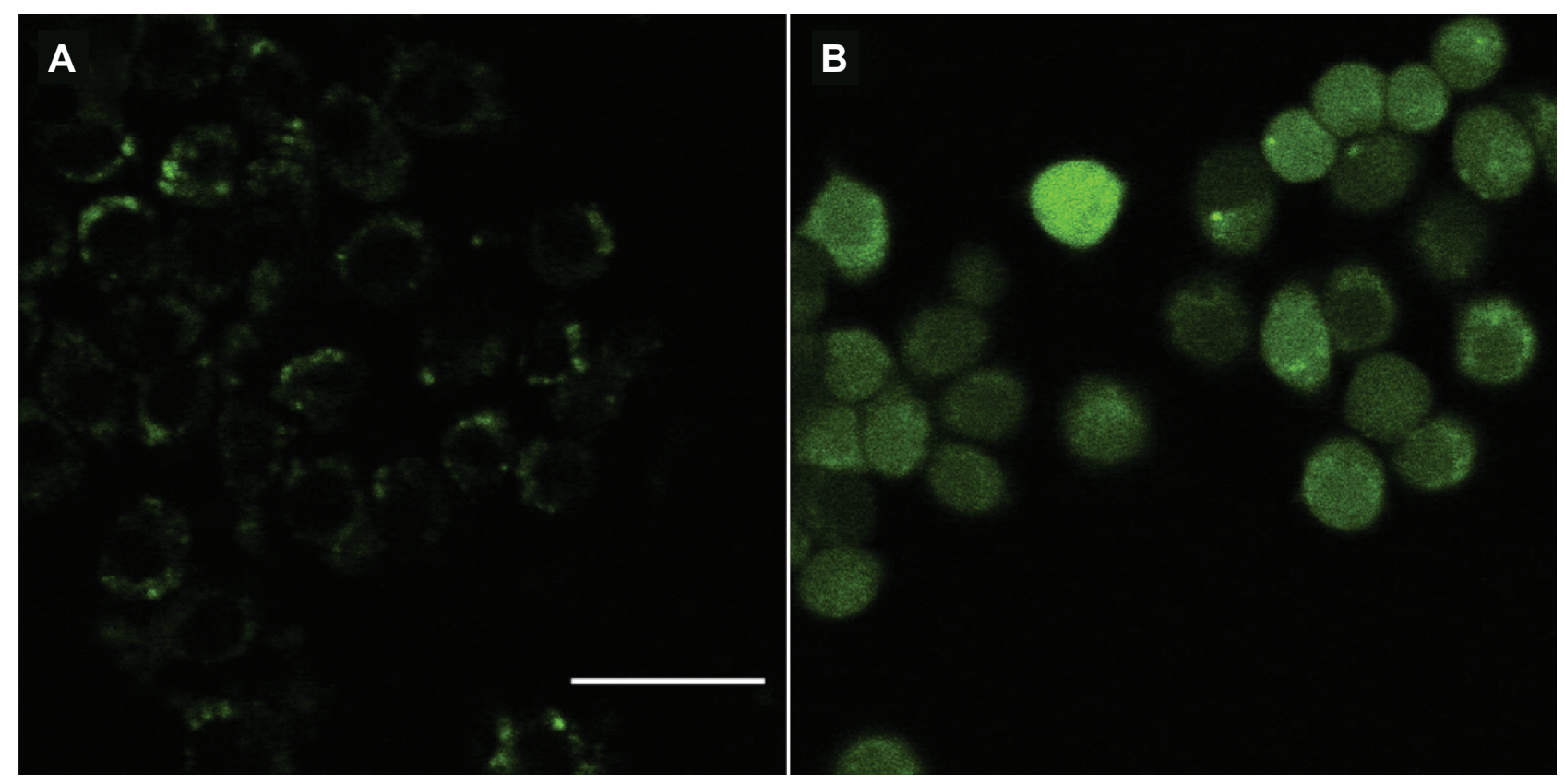

Figure 6 Functionalized fullerenes mediate photodynamic killing of cancer cells. Fluorescence micrographs of J774 cells that had been incubated with intracellular reactive oxygen species probe $\mathrm{H}_{2}$ DCFDA, illuminated with $5 \mathrm{~J} / \mathrm{cm}^{2}$ 405-nm laser, and imaged after $5 \mathrm{~min}$. A) $\mathrm{H}_{2}$ DCFDA without fullerene; B) BF4 for $24 \mathrm{~h}+\mathrm{H}_{2} D C F D A$. Scale bar is $100 \mu \mathrm{m}$. Copyright (C) 2007, Elsevier. Reprinted with permission from Mroz P, Pawlak A, Satti M, et al. Functionalized fullerenes mediate photodynamic killing of cancer cells: Type I versus Type II photochemical mechanism. Free Radic Biol Med. 2007;43(5):7I I-7I9.

a biological system, a key component in the new field of nanomedicine. ${ }^{7}$ Oberdörster conducted the first study that showed uncoated fullerenes to cause oxidative stress in the brain and depletion of glutathione levels in juvenile largemouth bass species. ${ }^{87}$ The initial study was performed with tetrahydrofuran-solubilized $\mathrm{nC}_{60}$ and a later study used water solubilized $\mathrm{nC}_{60}{ }^{88}$ Blickley and colleagues concluded that aqua-nC ${ }_{60}$ affects the oxidative stress response of adult and larval Fundulus heteroclitus. ${ }^{89}$ However, these studies were performed on nonfunctionalized fullerenes but nevertheless serve as a reminder on the importance of conducting toxicity assays on functionalized fullerenes which have potential for clinical use.

In another preclinical study on acute oral administration of fullerenes in mammals (Sprague-Dawley rats), fullerenes were administered once orally to a single group of male and female at a dose level of $2,000 \mathrm{mg} / \mathrm{kg}$. No deaths were observed and the body weights in both sexes of $2,000 \mathrm{mg} / \mathrm{kg}$ group increased in a similar pattern to the control group. In this case, they concluded that fullerenes did not induce acute oral toxicity, nor in vitro genotoxicity..$^{90}$ Another report indicated that carbon based nanomaterials with different geometric structures (nanotubes versus fullerenes) exhibit quite different cytotoxicity and bioactivity in vitro, although they may not be accurately reflected in the comparative toxicity in vivo. ${ }^{91}$ It is interesting to note that Colvin and colleagues hypothesized that sparingly soluble fullerenes will cause oxidative damage to cellular membranes even at relatively low concentrations, and that the resulting toxicity will diminish as the fullerene cage becomes more fully derivatized and water soluble..$^{92}$ They subsequently reported that cytotoxic activity of $\mathrm{THF} / \mathrm{C}_{60}$ occurred through ROS-mediated cell membrane lipid peroxidation. ${ }^{93}$ This reiterates the importance of functionalized fullerenes which have a high degree of solubility in water. For instance, our in vitro studies on supramolecular structures of AF-1 in the concentration range 10-200 $\mu \mathrm{M}$ did not reveal any toxicity. ${ }^{38}$ In an in vivo model, DF-1 had no apparent adverse effects on normal zebrafish morphology or viability throughout the concentration range tested $(1-1,000 \mu \mathrm{mol} / \mathrm{L}) .^{40}$

In a review article, Nielsen and colleagues describe fullerenes as a "double-edged sword," having beneficial effects at low concentrations, but at high concentrations they may be able to induce inflammation and if chronic, may promote development of cancer. ${ }^{94}$ They conclude that the current data suggests that direct DNA-damaging effects are low, but formation of ROS may cause inflammation and genetic damage. As a result, dose-dependency determines whether effects can be beneficial or harmful. Also, the need to tightly control ROS-dependent biological effects of different fullerene preparations can be a challenge in their potential 
development for therapeutic use and clearly represents one of the principal goals. ${ }^{95}$ The aspect of toxicity of fullerene derivatives is clearly a contentious issues and there are several other studies and reviews which focus on both the absence and presence of toxicity on various fullerenes derivatives. ${ }^{96-107}$ The crucial aspect is not to interpret toxicity reports from various functionalized fullerenes, concentrations, in vitro or in vivo models as a concluding answer but rather conduct specific toxicity assays based on the final application of interest.

Recently, Wick and colleagues ${ }^{107}$ demanded that future exposure and mechanistic studies should involve good characterization of the materials, careful preparation of each experimental design and special attention must be given to the solvents and media used within these studies. They concluded that many published data for which these prerequisites have not been fulfilled were not useful for an unbiased discussion of nanomaterial toxicity. A majority of the research papers that we have discussed in the review clearly clarify the need for further toxicity assays before claiming the clinical use of their functionalized fullerenes. On the positive side, some of these nanomaterials including certain functionalized fullerenes may provide great improvements over existing medications and improve the quality of life for patients with severe diseases such as cancer or in cases of major disasters that can cause severe radiation exposure. All new technologies may bear a high amount of unknown factors along with lack of long term exposure risks but if the benefits offered are dramatic then they could overcome certain drawbacks.

\section{Conclusions}

In recent years, functionalized fullerenes have drastically changed the face of biological applications of $\mathrm{C}_{60}$. The credit goes to the creative and collaborative efforts of scientists who specialize in fullerene synthesis and nanomedicine. This merge is critical for both the chemistry behind designing the most effective modifications on the fullerenes and the biology behind successful diagnosis and therapeutic outcomes in disease. In this review we have provided an overview and an exhaustive list of the ever expanding research studies on using functionalized fullerenes to deliver drugs to diseased cells, act as an antioxidant to quench ROS, function as MRI contrast agents, and enhance the quality of noninvasive imaging of specific portions of the human body and for a multitude of other uses in biomedicine. At this current stage, these studies are limited to in vitro and in vivo preclinical data and have not reached the stage of clinical trials.
This is true not just for functionalized fullerenes but for a variety of other nanomaterials that are currently investigated for use in humans. One of the major reasons for the inability of these nanomaterials to translate into clinically approved drugs is the lack of consistent data on the toxicity profiles on animal models. However, with the rapid technological advancement in the field of nanomedicine, this scenario could change in the coming years so that the unique features of various functionalized fullerenes could be exploited in a clinical setting.

\section{Acknowledgments}

The research studies on the amphiphilic fullerenes were supported by grants from NASA (NNJ05HE75A), DoD/ TATRC (W81XWH-04-20035T5), and DoD/TATRC (DAMD17-01-2-0047). The authors would like to extend their thanks to the publishers from whom permissions were obtained for reproducing figures. The authors report no conflicts of interest in this work.

\section{References}

1. Kroto HW, Heath JR, O'Brien SC, Curl RF, Smalley RE. $\mathrm{C}_{60}$ : Buckminsterfullerene. Nature. 1985;318:162-163.

2. Ruoff RS, Tse DS, Malhotra R, Lorents DC. Solubility of fullerene $\left(C_{60}\right)$ in a variety of solvents. J Phys Chem. 1993;97:3379-3383.

3. Sivaraman N, Dhamodaran R, Kaliappan I, Srinivassan TG, Rao PRV, Mathews CK. Solubility of $\mathrm{C}_{60}$ in organic solvents. J Org Chem. 1992;57:6077-6079.

4. Wilson SR. Biological aspects of fullerenes. In: Kadish KM, Ruoff RS, editors. Fullerenes: Chemistry, physics and technology. New York, NY: John Wiley and Sons, Inc; 2000. p. 431-436.

5. Da Ros T, Prato, M. Medicinal chemistry with fullerenes and fullerene derivatives. Chem Commun. 1999;8:663-669.

6. Jensen AW, Wilson SR, Schuster DI. Biological applications of fullerenes - A review. Bioorg Med Chem. 1996;4:767-779.

7. Riehemann K, Schneider SW, Luger TA, Godin B, Ferrari M, Fuchs H. Nanomedicine - challenge and perspectives. Angew Chem Int Ed Engl. 2009;48(5):872-897.

8. Caruthers SD, Wickline SA, Lanza GM. Nanotechnological applications in medicine. Curr Opin Biotechnol. 2007;18(1):26-30.

9. Jain KK. Role of nanobiotechnology in the development of personalized medicine. Nanomed. 2009;4(3):249-252.

10. Torchilin VP. Multifunctional nanocarriers. Adv Drug Deliv Rev. 2006;58(14):1532-1555.

11. Gregoriadis G. Liposomes as Drug Carriers: Recent Trends and Progress. New York, NY: John Wiley \& Sons; 1988.

12. Rolland A. Pharmaceutical Particulate Carriers. New York, NY: Marcel Dekker; 1993.

13. Brettreich M, Hirsch A. A highly water-soluble dendro[60]fullerene. Tetrahedron Lett. 1998;39:2731-2734.

14. Brettreich M, Burghardt S, Bottcher C, Bayerl T, Bayerl S, Hirsch A. Globular Amphiphiles: Membrane-forming hexaadducts of $\mathrm{C}_{60}$. Angew Chem Int Ed. 2000;39:1845-1848.

15. Burghardt S, Hirsch A, Schade B, Ludwig K, Bottcher C. Switchable supramolecular organization of structurally defined micelles based on an amphiphilic fullerene. Angew Chem Int Ed. 2005;44:2976-2979.

16. Klumpp C, Kostarelos K, Prato M, Bianco A. Functionalized carbon nanotubes as emerging nanovectors for the delivery of therapeutics. Biochim Biophys Acta. 2006;1758:404-412. 
17. Shi X, Thomas TP, Myc LA, Kotlyar A, Baker JR Jr. Synthesis, characterization, and intracellular uptake of carboxyl-terminated poly(amidoamine) dendrimer-stabilized iron oxide nanoparticles. Phys Chem Chem Phys. 2007;9:5712-5720.

18. Nishiyama N, Kataoka K. Current state, achievements, and future prospects of polymeric micelles as nanocarriers for drug and gene delivery. Pharmacol Ther. 2006;112:630-648.

19. Villalonga-Barber C, Micha-Screttas M, Steele BR, Georgopoulos A, Demetzos C. Dendrimers as biopharmaceuticals: synthesis and properties. Curr Top Med Chem. 2008;8:1294-1309.

20. Lal S, Clare SE, Halas NJ. Nanoshell-enabled photothermal cancer therapy: impending clinical impact. Acc Chem Res. 2008;41:1842-1851.

21. Barratt G. Colloidal drug carriers: achievements and perspectives. Cell Mol Life Sci. 2003;60:21-37.

22. Larocque J, Bharali DJ, Mousa SA. Cancer detection and treatment: The role of nanomedicines. Mol Biotechnol. 2009;42(3):358-366.

23. Schoenhagen P, Conyers JL. Nanotechnology and atherosclerosis imaging: emerging diagnostic and therapeutic applications. Recent Pat Cardiovasc Drug Discov. 2008;3(2):98-104.

24. Buxton DB. Nanomedicine for the management of lung and blood diseases. Nanomed. 2009;4(3):331-339.

25. Farokhzad OC, Langer R. Impact of nanotechnology on drug delivery ACS Nano. 2009;3(1):16-20.

26. Krusic PJ, Wasserman E, Keizer PN, Morton JR, Preston KF. Radical reactions of $\mathrm{C}_{60}$. Science. 1991;254(5035):1183-1185.

27. Lucente-Schultz RM, Moore VC, Leonard AD, et al. Antioxidant single-walled carbon nanotubes. J Am Chem Soc. 2009;131(11): 3934-3941.

28. Yin JJ, Lao F, Fu PP, et al. The scavenging of reactive oxygen species and the potential for cell protection by functionalized fullerene materials. Biomaterials. 2009;30(4):611-621.

29. Lucignani G. Nanoparticles for concurrent multimodality imaging and therapy: The dawn of new theragnostic synergies. Eur J Nucl Med Mol Imaging. 2009;36(5):869-874.

30. Jensen AW, Wilson SR, Schuster DI. Biological applications of fullerenes. Bioorg Med Chem. 1996;4(6):767-779.

31. Tagmatarchis N, Shinohara H. Fullerenes in medicinal chemistry and their biological applications. Mini Rev Med Chem. 2001;1(4) 339-348.

32. Nakamura E, Isobe H. Functionalized fullerenes in water. The first 10 years of their chemistry, biology, and nanoscience. Acc Chem Res. 2003;36:807-815.

33. Bosi S, Da Ros T, Spalluto G, Prato M. Fullerene derivatives: an attractive tool for biological applications. Eur J Med Chem. 2003; 38(11-12):913-923.

34. Hirsch A. Fullerene derivatives for medical applications. In: Kuzmany H, Fink J, Mehring M, Roth S. editors. Electronic Properties of Novel Nanostructures. AIP Conf. Proc 2005: XIX International Winterschool/ Euroconference on Electronic Properties of Novel Materials; 2005 Mar 12-19; Kirchberg, Tirol, Austria. Berlin: Springer; 2005. p. $581-585$.

35. Satoh M, Takayanagi I. Pharmacological studies on fullerene $\left(\mathrm{C}_{60}\right)$, a novel carbon allotrope, and its derivatives. J Pharmacol Sci. 2006;100(5):513-518.

36. Djordjević A, Bogdanović G, Dobrić S. Fullerenes in biomedicine. J BUON. 2006;11(4):391-404.

37. Bakry R, Vallant RM, Najam-ul-Haq M, et al. Medicinal applications of fullerenes. Int J Nanomedicine. 2007;2(4):639-649.

38. Partha R, Lackey M, Hirsch A, Casscells SW, Conyers JL. Self assembly of amphiphilic $\mathrm{C}_{60}$ fullerene derivatives into nanoscale supramolecular structures. J Nanobiotechnology. 2007;5:6.

39. Partha R, Mitchell LR, Lyon JL, Joshi PP, Conyers JL. Buckysomes: fullerene-based nanocarriers for hydrophobic molecule delivery. $A C S$ Nano. 2008;2(9):1950-1958.

40. Daroczi B, Kari G, McAleer MF, Wolf JC, Rodeck U, Dicker AP. In vivo radioprotection by the fullerene nanoparticle DF-1 as assessed in a zebrafish model. Clin Cancer Res. 2006;12(23):7086-7091.
41. Zakharian TY, Seryshev A, Sitharaman B, Gilbert BE, Knight V, Wilson LJ. A fullerene-paclitaxel chemotherapeutic: synthesis, characterization, and study of biological activity in tissue culture. J Am Chem Soc. 2005;127(36):12508-12509.

42. Nakamura E, Isobe H, Tomita N, Sawamura M, Jinno S, Okayama H. Functionalized fullerene as an artificial vector for transfection. Angew Chem Int Ed. 2000;39:4254-4257.

43. Isobe H, Tomita N, Jinno S, Okayama H, Nakamura E. Synthesis and transfection capability of multi-functionalized fullerene polyamine. Chem Lett. 2001;1214-1215.

44. Isobe H, Nakanishi W, Tomita N, Jinno S, Okayama H, Nakamura E. Nonviral gene delivery by tetraamino fullerene. Mol Pharm. 2006; 3(2):124-134.

45. Isobe H, Nakanishi W, Tomita N, Jinno S, Okayama H, Nakamura E. Gene delivery by aminofullerenes: Structural requirements for efficient transfection. Chem Asian J. 2006;1:167-175.

46. Sitharaman B, Zakharian TY, Saraf A, et al. Water-soluble fullerene $\left(\mathrm{C}_{60}\right)$ derivatives as nonviral gene-delivery vectors. Mol Pharm. 2008;5(4):567-578.

47. Bianco A, Da Ros T, Prato M, Toniolo C. Fullerene-based amino acids and peptides. J Pept Sci. 2001;7(4):208-219.

48. Yang J, Alemany LB, Driver J, Hartgerink JD, Barron AR. Fullerenederivatized amino acids: synthesis, characterization, antioxidant properties, and solid-phase peptide synthesis. Chemistry. 2007;13(9): 2530-2545.

49. Yang J, Wang K, Driver J, Yang J, Barron AR. The use of fullerene substituted phenylalanine amino acid as a passport for peptides through cell membranes. Org Biomol Chem. 2007;5(2):260-266.

50. Hu Z, Guan W, Wang W, Huang L, Xing H, Zhu Z. Protective effect of a novel cystine $\mathrm{C}(60)$ derivative on hydrogen peroxide-induced apoptosis in rat pheochromocytoma PC12 cells. Chem Biol Interact. 2007;167(2):135-144.

51. Hu Z, Guan W, Wang W, Huang L, Xing H, Zhu Z. Synthesis of beta-alanine $\mathrm{C}_{60}$ derivative and its protective effect on hydrogen peroxide-induced apoptosis in rat pheochromocytoma cells. Cell Biol Int. 2007;31(8):798-804.

52. Ji H, Yang Z, Jiang W, et al. Antiviral activity of nano carbon fullerene lipidosome against influenza virus in vitro. J Huazhong Univ Sci Technolog Med Sci. 2008;28(3):243-246.

53. Ikeda A, Sue T, Akiyama M, et al. Preparation of highly photosensitizing liposomes with fullerene-doped lipid bilayer using dispersion-controllable molecular exchange reactions. Org Lett. 2008;10(18):4077-4080.

54. Doi Y, Ikeda A, Akiyama M, et al. Intracellular uptake and photodynamic activity of water-soluble [60]- and [70]fullerenes incorporated in liposomes. Chemistry. 2008;14(29):8892-8897.

55. Lens M, Medenica L, Citernesi U. Antioxidative capacity of C(60) (buckminsterfullerene) and newly synthesized fulleropyrrolidine derivatives encapsulated in liposomes. Biotechnol Appl Biochem. 2008;51(Pt 3):135-140.

56. Maeda R, Noiri E, Isobe $\mathrm{H}$, et al. A water-soluble fullerene vesicle alleviates angiotensin II-induced oxidative stress in human umbilical venous endothelial cells. Hypertens Res. 2008;31(1):141-151.

57. Bolskar RD, Benedetto AF, Husebo LO, et al. First soluble M@ $\mathrm{C}_{60}$ derivatives provide enhanced access to metallofullerenes and permit in vivo evaluation of $\mathrm{Gd} @ \mathrm{C}_{60}[\mathrm{C}(\mathrm{COOH}) 2] 10$ as a MRI contrast agent. J Am Chem Soc. 2003;125(18):5471-5478.

58. Tóth E, Bolskar RD, Borel A, et al. Water-soluble gadofullerenes: toward high-relaxivity, $\mathrm{pH}$-responsive MRI contrast agents. J Am Chem Soc. 2005;127(2):799-805.

59. Sitharaman B, Tran LA, Pham QP, et al. Gadofullerenes as nanoscale magnetic labels for cellular MRI. Contrast Media Mol Imaging. 2007;2(3):139-146.

60. Bolskar RD. Gadofullerene MRI contrast agents. Nanomed. 2008;3(2): 201-213.

61. Fatouros PP, Corwin FD, Chen ZJ, et al. In vitro and in vivo imaging studies of a new endohedral metallofullerene nanoparticle. Radiology. 2006;240(3):756-764 
62. Mroz P, Pawlak A, Satti M, et al. Functionalized fullerenes mediate photodynamic killing of cancer cells: Type I versus Type II photochemical mechanism. Free Radic Biol Med. 2007;43(5):711-719.

63. Mroz P, Tegos GP, Gali H, Wharton T, Sarna T, Hamblin MR. Photodynamic therapy with fullerenes. Photochem Photobiol Sci. 2007;6(11):1139-1149.

64. Qu X, Komatsu T, Sato T, et al. Structure, photophysical property, and cytotoxicity of human serum albumin complexed with tris(dicarboxy methylene)[60]fullerene. Bioconjug Chem. 2008;19(8):1556-1560.

65. Rancan F, Rosan S, Boehm F, et al. Cytotoxicity and photocytotoxicity of a dendritic $\mathrm{C}(60)$ mono-adduct and a malonic acid $\mathrm{C}(60)$ tris-adduct on Jurkat cells. J Photochem Photobiol. 2002; B67: $157-162$.

66. Dugan LL, Gabrielsen JK, Yu SP, Lin TS, Choi DW. Buckminsterfullerenol free radical scavengers reduce excitotoxic and apoptotic death of cultured cortical neurons. Neurobiol Dis. 1996;3(2):129-135.

67. Tsai MC, Chen YH, Chiang LY. Polyhydroxylated $\mathrm{C}_{60}$, fullerenol, a novel free-radical trapper, prevented hydrogen peroxide- and cumene hydroperoxide-elicited changes in rat hippocampus in-vitro. J Pharm Pharmacol. 1997;49:438-445.

68. Lai HS, Chen WJ, Chiang LY. Free radical scavenging activity of fullerenol on the ischemia-reperfusion intestine in dogs. World J Surg. 2000;24:450-454.

69. Injac R, Boskovic M, Perse M, et al. Acute doxorubicin nephrotoxicity in rats with malignant neoplasm can be successfully treated with fullerenol $\mathrm{C}_{60}(\mathrm{OH}) 24$ via suppression of oxidative stress. Pharmacol Rep. 2008;60(5):742-749.

70. Injac R, Perse M, Cerne M, et al. Protective effects of fullerenol $\mathrm{C}_{60}(\mathrm{OH}) 24$ against doxorubicin-induced cardiotoxicity and hepatotoxicity in rats with colorectal cancer. Biomaterials. 2009;30(6): 1184-1196.

71. Dugan LL, Turetsky DM, Du C, et al. Carboxyfullerenes as neuroprotective agents. Proc Natl Acad Sci U S A. 1997;94(17):9434-9439. Erratum in: Proc Natl Acad Sci U S A 1997;94(22):12241.

72. Murthy CN, Choi SJ, Geckeler KE. Nanoencapsulation of [60] fullerene by a novel sugar-based polymer. $J$ Nanosci Nanotechnol. 2002;2(2):129-132.

73. Tykhomyrov AA, Nedzvetsky VS, Klochkov VK, Andrievsky GV. Nanostructures of hydrated $\mathrm{C}_{60}$ fullerene $\left(\mathrm{C}_{60} \mathrm{HyFn}\right)$ protect rat brain against alcohol impact and attenuate behavioral impairments of alcoholized animals. Toxicology. 2008;246(2-3):158-165.

74. Amirshahi N, Alyautdin RN, Sarkar S, et al. Fullerene-based low toxic nanocationite particles (porphyrin adducts of cyclohexyl fullerene- $\mathrm{C}(60)$ ) to treat hypoxia-induced mitochondrial dysfunction in mammalian heart muscle. Arch Med Res. 2008;39(6):549-559.

75. Bisaglia M, Natalini B, Pellicciari R, et al. C3-fullero-trismethanodicarboxylic acid protects cerebellar granule cells from apoptosis. J Neurochem. 2000;74:1197-1204.

76. Lin AM, Chyi BY, Wang SD, et al. Carboxyfullerene prevents iron-induced oxidative stress in rat brain. Neurochem. 1999;72(4): 1634-1640.

77. Monti D, Moretti L, Salvioli S, et al. $\mathrm{C}_{60}$ carboxyfullerene exerts a protective activity against oxidative stress-induced apoptosis in human peripheral blood mononuclear cells. Biochem Biophys Res Commun. 2000;277(3):711-717.

78. Santos SG, Santana JV, Maia FF Jr, et al. Adsorption of ascorbic acid on the $\mathrm{C}_{60}$ fullerene. J Phys Chem B. 2008;112(45):14267-14272.

79. Gonzalez KA, Wilson LJ, Wu W, Nancollas GH. Synthesis and in vitro characterization of a tissue-selective fullerene: vectoring $\mathrm{C}(60)(\mathrm{OH})(16) \mathrm{AMBP}$ to mineralized bone. Bioorg Med Chem. 2002;10(6):1991-1997.

80. Bianco A, Bertolini T, Crisma M, et al. Beta-turn induction by $\mathrm{C}_{60}$-based fulleroproline: synthesis and conformational characterization of Fpr/Pro small peptides. J Pept Res. 1997;50(3):159-170.

81. Marcorin GL, Da Ros T, Castellano S, et al. Design and synthesis of novel [60]fullerene derivatives as potential HIV aspartic protease inhibitors. Org Lett. 2000;2(25):3955-3958.
82. Marchesan S, Da Ros T, Spalluto G, Balzarini J, Prato M. Anti-HIV properties of cationic fullerene derivatives. Bioorg Med Chem Lett. 2005;15(15):3615-3618.

83. Pellarini F, Pantarotto D, Da Ros T, Giangaspero A, Tossi A, Prato M. A novel [60]fullerene amino acid for use in solid-phase peptide synthesis. Org Lett. 2001;3(12):1845-1848.

84. Pantarotto D, Tagmatarchis N, Bianco A, Prato M. Synthesis and biological properties of fullerene-containing amino acids and peptides. Mini Rev Med Chem. 2004;4(7):805-814.

85. Singh S, Nalwa HS. Nanotechnology and health safety - toxicity and risk assessments of nanostructured materials on human health. J Nanosci Nanotechnol. 2007;7(9):3048-3070.

86. Oberdörster E. Manufactured nanomaterials (fullerenes, $\mathrm{C}_{60}$ ) induce oxidative stress in the brain of juvenile largemouth bass. Environ Health Perspect. 2004;112(10):1058-1062.

87. Zhu S, Oberdorster E, Haasch ML. Toxicity of an engineered nanoparticle (fullerene, $\mathrm{C}_{60}$ ) in two aquatic species, daphnia and fathead minnow. Mar Environ Res. 2006;62(Suppl):S5-S9.

88. Blickley TM, McClellan-Green P. Toxicity of aqueous fullerene in adult and larval Fundulus heteroclitus. Environ Toxicol Chem. 2008;27(9):1964-1971.

89. Mori T, Takada H, Ito S, Matsubayashi K, Miwa N, Sawaguchi T. Preclinical studies on safety of fullerene upon acute oral administration and evaluation for no mutagenesis. Toxicology. 2006;225(1): $48-54$.

90. Jia G, Wang H, Yan L, et al. Cytotoxicity of carbon nanomaterials: single-wall nanotube, multi-wall nanotube, and fullerene. Environ $\mathrm{Sci}$ Technol. 2005;39:1378-1383.

91. Sayers CM, Fortner JD, Guo W, Lyon D, Colvin VL. The differential cytotoxicity of water-soluble fullerenes. Nano Lett. 2004;4:1881-1887.

92. Sayers CM, Gobin AM, Ausman KD, Mendez J, West JL, Colvin VL. Nano- $\mathrm{C}_{60}$ cytotoxicity is due to lipid peroxidation. Biomaterials. 2005;26:7587-7595.

93. Nielsen GD, Roursgaard M, Jensen KA, Poulsen SS, Larsen ST. In vivo biology and toxicology of fullerenes and their derivatives. Basic Clin Pharmacol Toxicol. 2008;103(3):197-208.

94. Markovic Z, Trajkovic V. Biomedical potential of the reactive oxygen species generation and quenching by fullerenes $\left(\mathrm{C}_{60}\right)$. Biomaterials. 2008;29(26):3561-3573.

95. Yamada T, Jung DY, Sawada R, Matsuoka A, Nakaoka R, Tsuchiya T. Effects intracerebral microinjection and intraperitoneal injection of [60]fullerene on brain functions differ in rats. J Nanosci Nanotechnol. 2008;8(8):3973-3980.

96. Markovic Z, Todorovic-Markovic B, Kleut D, et al. The mechanism of cell-damaging reactive oxygen generation by colloidal fullerenes. Biomaterials. 2007;28(36):5437-5448.

97. Gharbi N, Pressac M, Hadchouel M, Szwarc H, Wilson SR, Moussa F. [60]fullerene is a powerful antioxidant in vivo with no acute or subacute toxicity. Nano Lett. 2005;5(12):2578-2585.

98. Bosi S, Feruglio L, Da Ros T, et al. Hemolytic effects of water-soluble fullerene derivatives. J Med Chem. 2004;47(27):6711-6715.

99. Foley S, Crowley C, Smaihi M, et al. Cellular localisation of a water-soluble fullerene derivative. Biochem Biophys Res Commun. 2002;294(1):116-119.

100. Kamat JP, Devasagayam TP, Priyadarsini KI, Mohan H, Mittal JP. Oxidative damage induced by the fullerene $\mathrm{C}_{60}$ on photosensitization in rat liver microsomes. Chem Biol Interact. 1998;114(3):145-159.

101. Roberts JE, Wielgus AR, Boyes WK, Andley U, Chignell CF. Phototoxicity and cytotoxicity of fullerol in human lens epithelial cells. Toxicol Appl Pharmacol. 2008;228(1):49-58.

102. Belgorodsky B, Fadeev L, Kolsenik J, Gozin M. Biodelivery of a fullerene derivative. Bioconjug Chem. 2007;18(4):1095-1100.

103. Rouse JG, Yang J, Barron AR, Monteiro-Riviere NA. Fullerenebased amino acid nanoparticle interactions with human epidermal keratinocytes. Toxicol In Vitro. 2006;20(8):1313-1320.

104. Kolosnjaj J, Szwarc H, Moussa F. Toxicity studies of fullerenes and derivatives. Adv Exp Med Biol. 2007;620:168-180. 
105. Wong-Ekkabut J, Baoukina S, Triampo W, Tang IM, Tieleman DP, Monticelli L. Computer simulation study of fullerene translocation through lipid membranes. Nat Nanotechnol. 2008;3(6):363-368.

106. Usenko CY, Harper SL, Tanguay RL. In vivo evaluation of carbon fullerene toxicity using embryonic zebrafish. Carbon N Y. 2007;45(9): 1891-1898.
107. Spohn P, Hirsch C, Hasler F, Bruinink A, Krug HF, Wick P. C fullerene: a powerful antioxidant or a damaging agent? The importance of an in-depth material characterization prior to toxicity assays. Environ Pollut. 2009;157(4):1134-1139.

International Journal of Nanomedicine

\section{Publish your work in this journal}

The International Journal of Nanomedicine is an international, peerreviewed journal focusing on the application of nanotechnology in diagnostics, therapeutics, and drug delivery systems throughout the biomedical field. This journal is indexed on PubMed Central, MedLine, CAS, SciSearch $\AA$, Current Contents ${ }^{\circledR} /$ Clinical Medicine,
Journal Citation Reports/Science Edition, EMBase, Scopus and the Elsevier Bibliographic databases. The manuscript management system is completely online and includes a very quick and fair peer-review system, which is all easy to use. Visit http://www.dovepress.com/ testimonials.php to read real quotes from published authors.

Submit your manuscript here: http://www.dovepress.com/international-journal-of-nanomedicine-journal 